\title{
Políticas linguísticas educacionais: o (não) lugar das tecnologias digitais no ensino/aprendizagem de línguas no ensino médio nas Diretrizes Curriculares Nacionais e na Base Nacional Comum Curricular
}

\author{
Educational linguistic policies: the (non) place of digital technologies in \\ the teaching / learning of languages in high school in the National \\ Curriculum Guidelines and in the Common National Curricular Base
}

Manoela Oliveira de Souza Santana ${ }^{1}$

\begin{abstract}
Resumo
Política Linguística é uma área de investigação recente que cuida de ideias, leis, práticas voltadas à manutenção, mudança, ensino, entre outros aspectos, concernentes à língua. Nesse contexto, destacamos as políticas linguísticas educacionais que lidam com o ensino e o uso das línguas nos sistemas educativos. Para a discussão que nos interessa neste artigo, questionamos de que modo documentos curriculares do Ensino Médio, referentes à Língua Portuguesa e à Língua Inglesa, como materialização de políticas linguísticas educacionais, a exemplo das Diretrizes Curriculares Nacionais da Educação Básica para o Ensino Médio (DCNEM) e de uma versão para o Ensino Médio da Base Nacional Comum Curricular (BNCC) publicada em 2018, têm assegurado um (não) lugar à efetividade do ensino-aprendizagem de línguas com tecnologias digitais. Por meio de um estudo qualitativo, comparativo, descritivo e reflexivo acerca desses documentos, vê-se que é premente na sociedade que as escolas integrem tecnologias digitais como potencializadoras do processo de aprendizagem. Durante a escolarização, no Ensino Médio, é possível empreender para que se tenha essa oportunidade na aprendizagem da língua materna e de uma segunda língua. Documentos curriculares nacionais podem contribuir para essa perspectiva, até mesmo com o propósito de fortalecer a intenção de outros documentos curriculares nacionais de possibilitar a inclusão dos sujeitos, na e pela língua, em contextos tecnológicos digitais.
\end{abstract}

Palavras-chave: Ensino/Aprendizagem de Línguas. Tecnologias. Referenciais Curriculares.

\begin{abstract}
Linguistic Policy is an area of recent research that takes care of ideas, laws, practices aimed at maintenance, change, teaching, among other aspects, concerning the language. In this context, we highlight the educational linguistic policies that deal with the teaching and use of languages in education systems. For the discussion that interests us in this article, we question how high school curriculum documents, referring to Portuguese and English, as materialization of educational linguistic policies, such as the National Curriculum Guidelines for Basic Education for High School (DCNEM) ) and a version for High School of the National Common Curriculum Base (BNCC) published in 2018, have ensured (not) a place to the effectiveness of teaching and learning languages with digital technologies. Through a qualitative, comparative, descriptive and reflective study about these documents, it is seen that it is urgent in society that schools integrate digital technologies as enhancing the learning process. During schooling, in high school, it is possible to undertake to have this opportunity in learning the mother tongue and a second language. National curriculum documents can contribute to this perspective, even with the purpose of strengthening the intention of other national curriculum documents to enable the inclusion of subjects, in and by language, in digital technological contexts.
\end{abstract}

Keywords: Language Teaching / Learning. Technologies. Curriculum references.

${ }_{1}^{1}$ Doutora em Língua e Cultura, Universidade Federal da Bahia, Gandu, Bahia, Brasil. Orcid: https://orcid.org/0000-0001-51490650. E-mail: maneftc4@yahoo.com.br 


\section{Introdução}

O objeto de estudo a ser discutido neste artigo diz respeito, no contexto das políticas linguísticas educacionais, ao (não) lugar do ensino-aprendizagem de línguas com tecnologias digitais em documentos curriculares nacionais concernentes ao Ensino Médio: DCNEM e uma versão da BNCC22. Essa discussão é pertinente, porque na égide da sociedade tecnológica, as vivências com as múltiplas linguagens solicitam novas perspectivas e contribuições de estudos linguísticos para o ensino de línguas com diferentes mídias, visto que estas facilitam a transposição de fronteiras, apresentando novas possibilidades para o uso da linguagem em práticas sociais que poderão incluir os sujeitos nas interações humanas.

Assim, é premente o empreendimento em políticas linguísticas educacionais, como uma especificidade de políticas linguísticas, que invistam nessa perspectiva de ensino. Entende-se que as DCNEM e a BNCC, como referenciais curriculares nacionais, podem contribuir para os professores efetivarem esse ensino, pois apresentam orientações à ação pedagógica.

Mas, nos questionamos de que modo documentos curriculares do Ensino Médio, referentes à língua portuguesa e a língua e inglesa, como materialização de políticas linguísticas educacionais, a exemplo das DCNEM e da BNCC, têm assegurado um (não) lugar para a efetividade do ensinoaprendizagem de línguas com tecnologias digitais?

A fim de se ter, não a única, mas uma certa resposta para essa pergunta, tem-se como objetivos neste artigo: descrever como as DCNEM e a BNCC propõem o ensino de línguas - Português e Inglês; estabelecer uma comparação entre os documentos no sentido de perceber qual o (não) lugar do ensinoaprendizagem de línguas com tecnologias digitais e refletir sobre a contribuição de documentos curriculares, como materialização de políticas linguísticas, no que se refere à efetividade do ensino de línguas com essas tecnologias.

Nesse sentido, far-se-á, no curso desta produção, uma abordagem comparativa entre os documentos curriculares selecionados numa perspectiva discursivo-argumentativa, apresentando as considerações de autores como: Calvet (1996) e Oliveira (2016) sobre políticas linguísticas e planificação linguística; Day e Savedra (2015) acerca de políticas linguísticas educacionais; Moita Lopes (2006) no que tange ao ensino e aprendizagem de línguas; Street (2014); Barton e Lee (2015), Rojo (2013) sobre os multiletramentos e Aragão, Beato e Santos (2012) em sua abordagem referente à formação docente

2Para a produção deste artigo, foi utilizada a versão da Base Nacional Comum Curricular (BNCC) para o Ensino Médio, instituída pela Resolução $n^{0}$ 4, de 17 de dezembro de 2018. 
para o trabalho com tecnologias digitais nesse ensino, estabelecendo diálogos com Cupani (2016) e Foucault (1983), ao se discutir tecnologias digitais para além de sua peculiaridade técnica. Servirão também à produção deste artigo as Diretrizes Curriculares Nacionais para o Ensino Médio (2012) e uma versão (para o Ensino Médio) da Base Nacional Comum Curricular (2018).

\section{Políticas linguísticas e políticas linguísticas educacionais: um olhar para o ensino de línguas com tecnologias digitais}

Lagares e Savedra (2013) abordam que há muitas referências para a compreensão do que sejam Políticas Linguísticas até porque estas, por vezes, se confundem com Planejamento Linguístico. Nessa perspectiva, apresentam conceitos desses aspectos numa relação de subordinação. "Política linguística é definida como sendo a determinação de grandes escolhas relativas às relações entre as línguas e determinadas sociedades, e planificação linguística como a política linguística posta em prática, representando um ato de autoridade" (LAGARES; SAVEDRA, 2013, p. 12). Citam como aporte teórico os estudos de Calvet (1996) que discutem política linguística como "[...]conjunto de decisões tomadas pelo poder público a respeito de quais línguas serão fomentadas ensinadas ou eventualmente reprimidas e eliminadas; de quais funções as línguas terão ou deveriam ter, de que espaços sociais ocuparão".

Oliveira (2016), numa perspectiva mais atual e tendo em vista o seu lugar de vivência, discute Políticas Linguísticas, integradas ao planejamento linguístico, como "[...] uma área das políticas públicas concebidas e executadas por instituições que têm ingerência na sociedade como os Estados, os governos, as igrejas, as empresas, as ONGs e associações, e até as famílias" (2016, p. 382), com fins de tomadas de decisões sobre as línguas como problema, como direito e como recurso. Essas três grandes perspectivas para a discussão sobre políticas linguísticas são apresentadas, segundo Oliveira (2016), por Richard Ruiz em 1984 no seu artigo Orientations in Language Planning.

O que Oliveira diz é interessante porque trata de políticas linguísticas como um empreendimento necessário à resolução de problemas relacionados ao uso da língua que interferem no direito à dignidade humana. No contexto educacional, é preciso assegurar lugares às políticas linguísticas, pois estas "[...] nos dão uma conexão entre as línguas e todo o resto do universo humano, seus interesses suas necessidades, suas visões de futuro" (OLIVEIRA, 2016, p. 386).

Como um apoio a essa necessidade, fala-se de Política Linguística Educativa, um componente de uma política linguística que se refere especificamente ao ensino de línguas, estando "[...] relacionada a toda decisão, tomada de agentes sociais no sentido de orientar o uso de uma ou mais línguas em concorrência em uma dada situação" (DAY e SAVEDRA, 2015, p. 561). 
Tem-se aqui um lugar oportuno para se pensar em língua como direito e como recurso, que segundo Oliveira (2016), integra a organização tecnologicamente diferenciada das oportunidades, como os aplicativos de celular, para o ensino-aprendizagem de línguas, tanto no que se refere à língua materna como a segunda língua.

Quando falamos em ensino-aprendizagem de línguas com tecnologias digitais, entendemos serem necessárias políticas linguísticas educacionais que favoreçam a inclusão do sujeito em contextos digitais. Em universos multissemióticos, é possível construir competências e habilidades para o uso formal da língua, podendo, simultaneamente, segundo Day e Savedra, "[...] construir correlativamente a cidadania, a igualdade de condições e direitos, a tolerância para com o outro e o diferente, as diferentes formas de saber e de acesso ao saber, trazer à tona os fundamentos políticos sociais, econômicos, culturais e jurídicos subjacentes às propostas emanadas pelo poder público para esse ensino" (2015, p. 561).

Globalização, Pós-Colonialismo, Sociedade Líquida, Identidades, Inter-pluri-multitransdisciplinar, entre outras, são expressões que leituras, discussões e pesquisas, também em contextos acadêmicos (em especial, quando lemos Pennycook (2001), Moita Lopes (2006), Rajagopalan (2003)), têm citado para contextualizar e justificar o mundo em que se vive no século XXI. A transcendência do paradigma positivista, cartesiano, eurocêntrico, segregador teve contribuições potenciais de avanços tecnológicos, até então, inimagináveis. Nesse sentido, as tecnologias digitais facilitam a transposição de fronteiras e apresentam novas perspectivas para a o uso da linguagem em práticas sociais.

Eis aquela pergunta com a qual sempre nos deparamos quando discutimos que a educação está estritamente imbricada ao contexto social, político, econômico e cultural no qual se vive: e a escola, como tem se reinventado no contexto vivenciado que torna contingente o espaço-tempo ordinário, abrindo novos meios de interação e ritmo de cronologias inéditas (LÉVY, 2003)?

Para essa reinvenção, destaca-se aqui a importância de os Documentos Curriculares fomentarem o trabalho com tecnologias sem a pretensão de prestigiar sobremaneira o acesso à técnica. Entende-se como relevante ter a tecnologia digital enquanto aliada para que se possa pensar e agir por meio dela. Fala-se, então, em tecnologia de produção, do signo, do poder, do corpo, considerando as técnicas do biopoder (FOUCAULT, 1983). Uma realidade polifacetada que nos afeta e desafia qualquer que seja nossa atividade (CUPANI, 2016).

Ainda há um forte apego à tecnologia tão somente como produção, como técnica, e a perspectiva do multiletramento, em nossas práticas, muitas vezes, é tímida quando se pensa no uso da hibridez entre as linguagens e as culturas dos sujeitos. Neste artigo, a tecnologia digital, necessariamente, não está 
sendo tratada tão somente como o acesso à técnica, mas para o despertar da constituição da subjetividade como assevera Foucault (1983). Este referencia as tecnologias de dominação expressas pela tecnologia do poder, do governo, do sexo e do corpo e pelas técnicas do biopoder.

Há, portanto, quatro grupos principais de "tecnologias", cada um deles tem uma matriz de razão prática. No texto As Tecnologias do Si (1983), Foucault apresenta quatro tipos de técnicas/tecnologias que são base para a formação das racionalidades práticas: são as tecnologias de produção, dos signos, de poder e de si. Tem como intenção investigar a relação entre as tecnologias de poder e as técnicas de si, retomando o conceito da tékhne grega. Situa a dimensão da tékhne e a constituição da subjetividade como o problema da filosofia Ocidental. A questão que move Foucault é a constituição de uma subjetividade por certos procedimentos técnicos de si (como dominação nas tecnologias de poder e do biopoder e, também, como liberdade na estética da existência).

(1) tecnologias de produção, que permitem produzir, transformar ou manipular as coisas; (2) tecnologias dos sistemas de signos, que permitem utilizar signos, sentidos, símbolos ou significação; (3) tecnologias de poder, que determinam a conduta dos indivíduos e os submetem a certos fins ou dominação, objetivando o sujeito; (4) tecnologias de si, que permitem aos indivíduos efetuar, com seus próprios meios ou com a ajuda de outros, um certo número de operações em seus próprios corpos, almas, pensamentos, conduta e modo de ser, de modo a transformá-los com o objetivo de alcançar um certo estado de felicidade, pureza, sabedoria, perfeição ou imortalidade. Estes quatro tipos de tecnologia dificilmente operam separadamente, apesar de cada uma delas estar associada a certa forma de dominação. Cada um implica certos modos de treinamento e modificação dos indivíduos, não apenas no sentido óbvio de aquisição de certas habilidades, mas também de aquisição de certas atitudes. Gostaria de mostrar tanto sua especificidade como sua interação constante. (FOUCAULT, 1983, p. 323)

O espaço digital apresenta-se suscetível a interações com a tecnologia da produção, por exemplo, quando se pensa no processamento do pensamento computacional para a produção técnica de determinada tarefa. Mas também possibilita receber e produzir sentidos por meio dos multiletramentos. Nesse processo, o sujeito poderá, com o auxílio do outro e da hibridez das múltiplas linguagens e culturas, ter autonomia e fazer uso da criticidade.

A intenção, a partir dessa abordagem, é valorizar as interações por meio de tecnologias digitas, para além do uso de artefatos, que dão sentido à cibercultura. Segundo Lemos (2008), esta, também chamada de cultura digital, é marcada por um pensar e agir por meio do uso de ferramentas eletrônicas. É peculiar ver as interações, desde a década de 70 , ganharem contornos mais políticos e comunicacionais hoje. Isso não é fruto apenas do desenvolvimento tecnológico, contudo, de uma confluência entre uma sociabilidade que emergia na década de 1960 e uma posição contrária a alguns discursos hegemônicos da era moderna, a razão, a ciência e a técnica. Dispõe, portanto, não apenas 
da transformação material e energética do mundo, mas da interferência destas na transformação comunicativa, política, social e cultural efetivamente.

Por cultura digital, em especial a partir dos anos 80 (século XX), entende-se uma interface entre as telecomunicações e a informática numa ampla e diversa troca de informações de dados comprimidos e digitalizados num fluxo global constante que fluem de um centro para uma periferia, bem como, horizontalmente, por meio de qualquer um que esteja interconectado nesse ambiente virtual, chamado ciberespaço (LÉVY, 2003). Essa cultura cria novas formas de interação e socialização (LEMOS, 2008). À distância de um click, as informações e imagens, que estão disponíveis online a todo o momento, mudam a percepção de tempo e espaço dos sujeitos, referência para a construção de suas memórias e identidades, tendo em vista novas maneiras de se sentir o mundo e (com) nele interagir.

Os cenários do ciberespaço e da cibercultura se tornaram um fenômeno econômico e cultural: redes mundiais de universitários e pesquisadores, redes empresariais, correios eletrônicos, comunidades virtuais e outras. Baseando-se na cooperação anarquista de milhares de centros informatizados no mundo, a Internet tornou-se o símbolo desse novo meio e comunicação e produção cultural: mais de 20 milhões de pessoas, essencialmente jovens, estavam conectados em 1994.

Nesse cenário, é relevante o investimento em políticas linguísticas por meio de políticas públicas e investimentos docentes com fins no aprimoramento do ensino e aprendizagem de línguas por meio de tecnologias digitais. Para Moita Lopes, "[...] a construção da aprendizagem está cada vez mais na participação em redes e na utilização de letramentos multissemióticos" (2006, p. 92). O trabalho com a língua, engajado, suscetível a potencializar o empoderamento, em agências de multiletramentos, referenciadas nas discussões de Street (2014), Barton e Lee (2015) e Rojo (2013), tem empreendido uma atenção sistemática e reflexiva sobre esse fato.

É emergente que saberes e fazeres docentes se aproximem mais dos multiletramentos, porque a vivência na sociedade atual impele a natureza política e ideológica no uso de linguagens, o que demanda motivação para a compreensão, transformação, criação e a percepção das relações de poder em práticas sociais as quais estão intimamente vinculadas aos aparatos tecnológicos disponíveis (ARAGÃO; BEATO; SANTOS, 2012).

Vive-se em um novo espaço em constante mudança, que está se organizando e reorganizando de acordo com as características da sociedade em rede, da globalização, da economia e da virtualidade, as quais produzem novas e sofisticadas formas de exclusão. É se inserindo criticamente nessa sociedade e buscando compreender seus instrumentos e dinâmicas de mobilização e expansão que se pode se apropriar e utilizar recursos e meios de interação para a emancipação humana. 
O investimento em políticas linguísticas educacionais é relevante nesse sentido. Para tanto, ter à disposição documentos curriculares, assim como a condição de interpretação crítica e uso adequado deles configuram-se como uma força ao ensino-aprendizagem de línguas com tecnologias digitais cujo enfoque deve estar na formação cidadã do sujeito.

\section{Documentos Curriculares Nacionais para o ensino/aprendizagem com tecnologias digitais no ensino médio: DCNEM E BNCC}

Com o propósito de assegurar a efetividade de políticas públicas para a educação, tem-se à disposição documentos como as Diretrizes Curriculares Nacionais e a Base Nacional Curricular Comum em sua versão preliminar. Dar-se-á ênfase à parte desses documentos que tratam do ensino de línguas (Língua Portuguesa e Língua Inglesa no Ensino Médio, dispensando uma atenção ao que se propõe para esse ensino com tecnologias digitais. Ainda que esse trabalho deva ser efetivado desde o início da educação básica do sujeito, o Ensino Médio (período de conclusão de uma etapa de escolarização), se configura como mais uma oportunidade de torná-lo possivel até porque a interação com essas tecnologias tem uma significação concreta para o público que se encontra nesse nível de ensino. Destacamos Língua Portuguesa e Língua Inglesa para apreciar se o ensino é pensado em perspectivas significativas nas duas línguas.

As Diretrizes são normas obrigatórias para a Educação Básica que orientam o planejamento curricular das escolas e sistemas de ensino, fixadas pelo Conselho Nacional de Educação (CNE). Têm origem na Lei de Diretrizes e Bases da Educação Nacional (LDBEN), 9394/96, que assinala ser incumbência da União "estabelecer, em colaboração com os Estados, Distrito Federal e os Municípios, competências e diretrizes para a educação infantil, o ensino fundamental e o ensino médio, que referenciarão os currículos e os seus conteúdos mínimos, podendo-se a assegurar a formação básica comum."

Essas Diretrizes integram as Novas Diretrizes Curriculares para o Ensino Médio. Nesse documento, observa-se que o currículo do Ensino Médio deve garantir: ações que promovam a educação tecnológica básica e a compreensão do significado da ciência das letras e das artes; o conhecimento do processo histórico de transformação da sociedade da cultura; o ensino e a aprendizagem da língua portuguesa (componente curricular obrigatório) como instrumento de comunicação, acesso ao conhecimento e exercício da cidadania; o ensino e a aprendizagem de uma língua estrangeira moderna (também componente obrigatório) e de uma outra língua estrangeira dentro das disponibilidades da instituição. 
Essa garantia deve se dar nas dimensões do trabalho, ciência, cultura e tecnologia. Para tanto, faz-se necessária a adoção de metodologias de ensino e de avaliação de aprendizagem que estimulem a iniciativa dos estudantes, assim como a organização dos conteúdos, metodologias e as formas de avaliação de modo que, ao final do Ensino Médio, o estudante demonstre "a) domínio dos princípios científicos e tecnológicos que presidem a produção moderna; b) conhecimento das formas contemporâneas de linguagem" (DCNEM, 2012, p. 197).

Vê-se que as diretrizes apresentam a Língua Portuguesa como componente transdisciplinar por entender que o conhecimento peculiar à disciplina a transcende e que por meio da linguagem, "[...] os sujeitos se constituem, constroem identidades, produzem conhecimento e agem de forma crítica no mundo" (DCEM, 2012, p. 36).

Não há uma abordagem reflexiva acerca da oferta de Língua Inglesa (como Língua Estrangeira) o que contemplaria uma discussão sobre as práticas de leitura, escrita e oralidade numa perspectiva glocal que integra a interculturalidade. Faz-se uma rápida referência ao trabalho com as diferentes mídias na escola, em seu artigo 16, quando as diretrizes ressaltam que o projeto político-pedagógico das unidades escolares, que ofertam o Ensino Médio, deve considerar:

(...)VIII - utilização de diferentes mídias como processo de dinamização dos ambientes de aprendizagem e construção de novos saberes; (...) XX - produção de mídias nas escolas a partir da promoção de atividades que favoreçam as habilidades de leitura e análise do papel cultural, político e econômico dos meios de comunicação na sociedade (...) (DCNEM, 2012, p. 199).

Sente-se a necessidade de indicativos sobre como o trabalho com o ensino e aprendizagem de línguas (Português e Inglês) pode contemplar as tecnologias digitais com vistas em um pensar e agir tecnologicamente no mundo para além do uso de tecnologias como artefato, mas como um evento que permite o que demanda o pensamento computacional, o conhecimento de programação e do uso ético de tecnologias digitais.

A Base Nacional Comum Curricular, outro documento tomado para análise, é um descritivo de conteúdos e saberes necessários para cada ano e segmento da Educação Básica. Para o Ensino Médio, o documento está passível de aprovação. Em relação ao trabalho com a Língua, no Ensino Médio, propõe competências, habilidades, campos, práticas de reflexões linguísticas e estéticas que envolvem a análise e uso de elementos discursivos, textuais, gramaticas, entre outros aspectos, como um meio para uma compreensão mais aprofundada dos modos de se expressar e participar do mundo, contemplando conhecimento e vida, as realidades dos estudantes e a diversidade social.

0 trabalho com a língua, nesse nível de ensino, tem como foco o letramento em todas as áreas do conhecimento, de modo que o estudante possa interagir em diferentes situações lendo, escrevendo, 
ouvindo e falando. Esse trabalho é proposto em cinco eixos: apropriação do sistema de escrita alfabético/ortográfico e de tecnologias da escrita, oralidade, leitura, escrita e análise linguística, sendo este último transversal aos demais.

Nesse contexto, junto a consumo e educação financeira, ética, direitos humanos e cidadania, sustentabilidade, culturas africanas e indígenas, as tecnologias digitais, aparecem como eixo integrador no ensino de línguas. A BNCC apresenta, assim, como responsabilidade da área de linguagens que o(a) educando(a) possa participar da vida pública e da produção cultural por meio de "músicas, danças, manifestações da cultura corporal do movimento, vídeos, marcas corporais, moda, rádios comunitárias, redes de mídia da internet, gírias e demais produções e práticas socioculturais que combinam linguagens e diferentes modos de estar juntos" (BNCC, 2018, p. 473).

Propõe-se o trabalho na área de Língua Portuguesa em campos de atuação, como práticas de estudo e pesquisa; jornalístico-midiático; atuação na vida pública; artístico. Esses campos contemplam a participação do sujeito em práticas de leitura/escuta, produção oral/escrita de textos que possibilitem a comunicação a distância e a compreensão de características e modos de produzir, divulgar e conservar informação, experimentar e criar novas linguagens e formas de interação social.

Vale ressaltar que entre as competências específicas de Língua Portuguesa no Ensino Médio (na área de Linguagens e suas Tecnologias), a BNCC apresenta:

Mobilizar práticas de linguagem no universo digital, considerando as dimensões técnicas, críticas, criativas, éticas e estéticas, para expandir as formas de produzir sentidos, de engajarse em práticas autorais e coletivas, e de aprender a aprender nos campos da ciência, cultura, trabalho, informação e vida pessoal e coletiva.(BNCC, 2018, p. 482)

Essa competência refere-se às práticas de linguagem em ambiente digital que têm trazido novas perspectivas de interações nos campos das interações humanas. Esse cenário tem sido interessante para que jovens desenvolvam a criticidade, a ética e a estética, usando as tecnologias da informação e da comunicação para selecionar, compreender, construir sentidos nesses campos.

Entende-se, assim, que não é pertinente apenas

possibilitar aos estudantes explorar interfaces técnicas (como a das linguagens de programação ou de uso de ferramentas e apps variados de edição de áudio, vídeo, imagens, de realidade aumentada, de criação de games, gifs, memes, infográficos etc.), mas também interfaces éticas que lhes permitam tanto triar e curar informações como produzir o novo com base no existente. (BNCC, 2018, p. 482)

Para a construção dessa competência, são feitos investimentos no trabalho com algumas habilidades como (BNCC, 2018, p. 489): 
(EM13LGG701) Explorar tecnologias digitais da informação e comunicação (TDIC), compreendendo seus princípios e funcionalidades, e mobilizá-las de modo ético, responsável e adequado a práticas de linguagem em diferentes contextos.

(EM13LGG702) Avaliar o impacto das tecnologias digitais da informação e comunicação (TDIC) na formação do sujeito e em suas práticas sociais, para fazer uso crítico dessa mídia em práticas de seleção, compreensão e produção de discursos em ambiente digital.

(EM13LGG703) Utilizar diferentes linguagens, mídias e ferramentas digitais em processos de produção coletiva, colaborativa e projetos autorais em ambientes digitais.

(EM13LGG704) Apropriar-se criticamente de processos de pesquisa e busca de informação, por meio de ferramentas e dos novos formatos de produção e distribuição do conhecimento na cultura de rede.

Ao apreciar essa competência e essas habilidades, entende-se que a BNCC tem um compromisso com a proposição de tecnologias digitais nas aulas de Língua Portuguesa tendo em vista o pensar e o agir humanos. A intenção é interagir com as diferentes linguagens, fazer uso de recursos relacionados à programação digital, praticar a colaboração à medida em que se vivencia o sertecnologicamente-no-mundo.

A competência e as habilidades referenciadas integram o trabalho com Língua Inglesa também pelo fato de este componente curricular integrar a área de Linguagens e suas Tecnologias. Vale destacar que 0 uso do inglês nas práticas pedagógicas permite que o estudante interaja na cultura digital, em estudos e pesquisas e amplie as perspectivas concernentes à vida pessoal e profissional. Nesse processo, há a possibilidade de integração com grupos multilíngues e multiculturais - que usam o inglês - no mundo global.

\begin{abstract}
No Ensino Médio, trata-se de expandir os repertórios linguísticos, multissemióticos e culturais dos estudantes, possibilitando o desenvolvimento de maior consciência e reflexão críticas das funções e usos do inglês na sociedade contemporânea - para problematizar os motivos pelos quais ela se tornou uma língua de uso global, por exemplo. Nas situações de aprendizagem do inglês, os estudantes podem reconhecer 0 caráter fluido, dinâmico e particular dessa língua, como também as marcas identitárias e de singularidade de seus usuários, de modo a ampliar suas vivências com outras formas de organizar, dizer e valorizar o mundo e de construir identidades. Aspectos como precisão, padronização, erro, imitação e domínio da língua são substituídos por noções mais abrangentes e relacionadas ao universo discursivo nas práticas situadas dentro dos campos de atuação, como inteligibilidade, singularidade, variedade, criatividade/ invenção e repertório. Trata-se de possibilitar aos estudantes cooperar e compartilhar informações e conhecimentos por meio da língua. (BRASIL, 2018, p. 477)
\end{abstract}

Nesses termos, para o trabalho com a língua estrangeira, a Base sugere que, no Ensino Médio, se deve investir na compreensão de que as línguas nos constituem como sujeitos e que expressam valores construídos nas práticas sociais. Nessa etapa, amplia-se a vivência com a(s) língua(s) em estudo nas diferentes práticas sociais e aprofunda-se a reflexão sobre as relações entre língua, cultura, política 
e sociedade. Cabe, ainda, a reflexão crítica e criativa sobre a participação em ações em que os sujeitos está inserido ou deseja inserir-se e os modos como essa inserção pode ser concretizada em diferentes línguas variedades linguísticas.

Nessa área, entre os campos de trabalho oferecidos, têm-se as práticas mediadas pela tecnologia de informação e comunicação que apontam para a participação do/a estudante na experimentação e criação de novas linguagens e modos de interação social com o uso das tecnologias mais atuais. Busca-se priorizar o trabalho com leitura/escuta, produção oral/escrita em língua estrangeira trabalho esse que estabelece vínculos que os sujeitos mantêm com os recursos tecnológicos para construir e usar o conhecimento de modo ético e responsável na comunidade.

Destaca-se aqui que a versão de 2018, não apresentou precisamente, competências e habilidades para Língua Inglesa, mas para a área de Linguagens e suas Tecnologias que contempla essa língua enquanto componente curricular. Numa outra versão da BNCC (2016), houve uma referência quanto aos objetivos de aprendizagem da língua estrangeira, mediados por questões reflexivas, que contemplam as "práticas mediadas pela tecnologia da informação e da comunicação" no Ensino Médio, a saber:

\footnotetext{
- Compreender modos e estratégias de participação em comunidades virtuais em língua estrangeira, identificando os temas abordados e os pontos de vista.

- Ler textos em língua estrangeira para participar de comunidades virtuais (instruções sobre ingresso, participação e desligamento de comunidades virtuais, políticas de comunidades, redes e sites, incluindo procedimentos para denunciar eventuais abusos, dentre outros), compreendendo as regras de participação e de segurança.

- Compreender modos de compartilhar e autorizar o uso consentido e de financiamento coletivo de projetos, identificando as regras de uso e maneiras de participar.

- Produzir textos escritos em língua estrangeira (comentários, chats, posts em fóruns de discussão, dentre outros) em comunidades virtuais, usando recursos linguístico-discursivos para expressas opiniões, solicitar informações ou esclarecimentos, fazer denúncias etc (BNCC, 2016, p. 80).
}

Desse modo, é pertinente a proposta de trabalho com tecnologias digitais na BNCC, pois suas orientações favorecem o redimensionamento do trabalho com as práticas leitoras e de produção textual por meio do uso dos hipertextos; ela incentiva o trabalho com a multimodalidade. O papel de leitor e autor assume uma nova referência, considerando a autonomia do sujeito que usa a língua, participando das práticas sociais no contexto de interação verbal. Contempla assim, um lugar para o trabalho com tecnologias digitais no ensino de línguas. Vê-se na proposta de língua estrangeira, um destaque para uma práxis que tenha no cerne os multiletramentos e a interculturalidade para o uso da língua, para se conviver em comunidade, em sua forma e função num viés social e crítico. 
É salutar sinalizar aqui que as competências gerais da BNCC fortalecem essas questões, em especial, as competências 4 e 5, respectivamente, a comunicação e a cultura digital, considerando que propõem:

\footnotetext{
Competência 4 (Comunicação): Utilizar diferentes linguagens - verbal (oral ou visual-motora, como Libras, e escrita), corporal, visual, sonora e digital-, bem como conhecimentos das linguagens artística, matemática e cientifica, para se expressar e partilhar informações, experiências, ideias e sentimentos em diferentes contextos e produzir sentidos que levem ao entendimento mútuo.

Competência 5 (Cultura Digital): Compreender, utilizar e criar tecnologias digitais de informação e comunicação de forma crítica, significativa, reflexiva e ética nas diversas práticas sociais (incluindo as escolares) para se comunicar, acessar e disseminar informações, produzir conhecimentos, resolver problemas e exercer protagonismo e autoria na vida pessoal e coletiva.
}

Pondera-se que o tratamento dado à cultura digital é bem oportuno já que há um investimento em currículos possíveis contemplarem a experiência computacional, o conhecimento dos algoritmos e a ética no uso de tecnologias digitais. Já o lugar dado aos multiletramentos precisa de redimensionamento porque faz referência a este como uma multiplicidade de linguagens, sem considerar a variedade de culturais nesse contexto como propõe a Pedagogia dos Multiletramentos (COPE E KALANTZIS, 2012). Somam-se aqui as observações de Rojo (2013) que essa Pedagogia considera também a diversidade da cultura glocal no cenário da hipermodernidade.

\section{0 (não) lugar do ensino-aprendizagem de línguas com tecnologias digitais em Documentos Curriculares Nacionais do Ensino Médio e na Base Nacional Comum Curricular}

Da análise dos documentos curriculares (DCNEM e BNCC), vê-se que houve um progressivo contemplar quanto ao tratamento dado por esses referenciais à tecnologia digital. As DCNEM citam a tecnologia como um princípio educacional quando tratam da necessidade de utilização de mídias para dinamizar os ambientes de aprendizagem com vistas na construção de novos saberes, promovendo a produção de mídias por meio das atividades promotoras da leitura e da escrita com fins sociais

A BNCC, por sua vez, fortalece esses aspectos somados, dando vazão ao trabalho didático com as tecnologias de modo que se possa integrar a técnica ao pensar e agir humanos com criticidade, no contexto glocal. Propõe a exploração de práticas de linguagem no universo digital, entrelaçando as dimensões técnicas, críticas, éticas e estéticas, de modo não apenas a desenvolver familiarização com esse universo, mas também a poder, gradativamente, expandir as formas de aprender e refletir sobre as realidades. 
Apresenta, entre as competências gerais, a Comunicação, valorizando o uso de multimídia analógicas e digitais, áudio, textos, imagens, gráficos e linguagens verbais, artísticas, científicas, matemáticas, cartográficas, corporais e multimodais de forma adequada, e a Cultura Digital no sentido de se compreender, utilizar e criar tecnologias digitais de forma criativa, significativa e ética para comunicar-se, acessar e produzir informações e conhecimentos, resolver problemas e expor protagonismo e autoria.

Por meio dessa análise, é possível dizer também que as DCNEM sinalizam o trabalho com tecnologias no Ensino Médio como um eixo geral, sem especificar o aspecto digital, nem em termos gerais nem no contexto desse ensino. A Base já destina um espaço maior dedicado a essa discussão.

Não se percebe nas DNCEM uma referência ao ensino de línguas (Língua Portuguesa e Língua Inglesa) com tecnologias digitais. A tecnologia é conceituada e tratada nesse documento numa perspectiva ontológica de transformação da natureza como realização inerente ao ser humano e como mediação no processo de produção da sua existência. É também evidenciada como um eixo integrador entre os conhecimentos de distintas naturezas.

Pode-se dizer que a Base se aproxima mais do cotidiano docente, do fazer pedagógico no que tange ao trabalho com tecnologias digitais no ensino de línguas. Essas aparecem, mais especificamente, em uma competência e habilidades propostas para Língua Portuguesa e Língua Inglesa. A tecnologia nesse contexto não é apresentada como um mero conteúdo, objetivo conceitual ou recurso para o trabalho didático.

Computadores, smartphones, blogs, facebook, whatsapp, emails, entre outros recursos e instrumentos a serviço das interações comunicativas no universo multissemiótico nos mostram que 0 ato discursivo não demanda, para sua materialização, tão necessariamente, da cultura tipográfica. Com um simples "click", ativando linguagens outras, agora, muitas vezes, usando o polegar (PRETTO, 2011), rompem-se paradigmas, fronteiras e estabelecem-se interações diversas.

A Base assume um forte sentido estratégico na ação dos professores, contemplando o que Preto (2011) aponta. Representa uma materialização de uma política linguística educacional que investe na efetividade do ensino de línguas com tecnologias digitais, o que implica interações no universo multissemiótico, inclusão digital dos sujeitos, aprendizagem mais significativa no uso real da língua. Espera-se que a Base seja aprovada e disponibilizada para o professor de que modo que este sujeito a compreenda e possa ter em suas orientações um referencial para a práxis.

Portanto, ambos documentos analisados são relevantes para o ensino de línguas em maior ou menor proporção e, até como possibilidade de complementação de outras propostas curriculares 
resultado de uma percepção do que determinado contexto tem precisado no momento. Eles poderão ajudar o docente a pensar e a empreender um ensino de línguas sensível à formação crítica do cidadão.

\section{Algumas considerações}

A discussão tecida neste artigo nos motiva a estar sempre relendo documentos curriculares no sentido de conhecê-los melhor e adequar os seus encaminhamentos -e, aqui, destacamos os das BNCC acerca do ensino de línguas -, ao trabalho pedagógico como uma expressão de política linguística educacional. A Base integra fundamentos e propostas metodológicas mais acessíveis aos docentes no que tange a esse ensino.

Vale ressalvar que a comparação que se teceu não tem como objetivo prestigiar um documento em detrimento de outro, mas dado o objetivo e a configuração de cada um, entendê-los como complementares: um faz uma referência mais generalizada sobre o trabalho com tecnologias nas aulas, e o outro nos aproxima da perspectiva desse trabalho.

É interessante notar, então, que não se deve alimentar embates sobre as relevâncias dos documentos, porque eles dialogam. A BNCC tem as DCNEM como referência e comunga com essas quando aponta a Língua Portuguesa como componente transdisciplinar já que o conhecimento peculiar à disciplina a transcende e revela que "[...] os sujeitos se constituem, constroem identidades, produzem conhecimento e agem de forma crítica no mundo" (BNCC, 2016, p. 36).

Tendo como referência algumas palavras de Oliveira (2016), podemos entender que documentos curriculares, como expressão de políticas públicas educacionais e, por extensão, de políticas linguísticas educacionais, têm implicações sobre os usos das línguas e geram demandas para intervenções sobre as próprias línguas que podem servir como um recurso essencial à inclusão do sujeito em interações de cidadania.

Documentos curriculares são aliados dessa inclusão, pois tratam da importância das tecnologias digitais no contexto educacional como um princípio (DCNEM), de aguçar o trabalho com a multissemiose, bem como se constituem norteadores para a ação pedagógica com as múltiplas linguagens e culturas (BNCC). Dessa forma, aprimorar os conhecimentos sobre eles e utilizá-los é oportuno já que são referenciais para formação docente, organização curricular e propostas de planejamento. 


\section{Referências}

ARAGÃO. Rodrigo; BEATO, Zelina; SANTOS, Tássia Ferreira. As TICS e o Ensino de Línguas. In: Seminário de Pesquisa e Extensão em Letras, 4., 2012. Anais. Ilhéus: UESC, 2012. p.1-20.

BARTON, D. e LEE, C. Linguagem online: textos e práticas digitais, São Paulo: Parábola Editorial, 2015. BRASIL. Ministério da Educação. Secretaria de Educação Básica. Diretrizes Curriculares Nacionais para a Educação Básica. Brasília: MEC/SEB, 2012.

Base Nacional Comum Curicular. Brasília: MEC/SEB. 2016.

Base Nacional Comum Curicular. Brasília: MEC/SEB. 2018.

CALVET, Louis-Jean. Les politiques linguistiques. Paris: Presses Universitaires de Frances, 1996.

COPE, B.; KALANTZIS, M. Literacies. Cambridge UK: Cambridge University Press, 2012.

CUPANI. A. Filosofia da Tecnologia: um convite. 3. ed. Florianópolis: Editora da UFSC, 2016.

DAY, Kelly Cristina Nascimento e SAVEDRA, Mônica Maria Guimarães SAVEDRA, Mônica Maria Guimarães. $O$ ensino de línguas estrangeiras no Brasil: questões de ordem político-linguísticas. Fórum Linguístico. Florianópolis, V. 12, n. 1. Jan/mar de 2015.

FOUCAULT, M (1983). O sujeito e o Poder. In Rabinow, P e Dreyfus. Foucault, Uma Trajetória Filosófica. Rio de Janeiro: Forense Universitária, 1995.

LAGARES, Xóan Carlos e SAVEDRA, Mônica Maria Guimarães. Política e planificação linguística: conceitos, terminologias e intervenções no Brasil. Revista Gravoatá. Rio de Janeiro Niterói, n. 32, 1. Sem. 2012.

LEMOS, André. Cibercultura, tecnologia e vida social na cultura contemporânea. Porto Alegre: Sulina, $4^{\text {a }}$ edição, 2008.

LÉVY, Pierre. Cibercultura. Tradução de Carlos Irineu da Costa. São Paulo: Editora 34, 2000.

MOITA LOPES, L. P. (Org.) Por uma Linguística Aplicada Indisciplinar. São Paulo: Parábola Editorial, 2006.

OLIVEIRA, Gilvan Müller. Políticas linguísticas: uma entrevista com Gilvan Müller de Oliveira. Revel, v. 14, n. 26, 2016.

PENNYCOOK, A. A. Critical Applied Linguistics: a critical introduction. Mahwah, NJ: Lawrence Erlbaum Associates, 2001.

PRETTO. Nelson. O desafio de educar na era digital. Revista Portuguesa de Educação, CIED, Universidade do Minho, 2011.

RAJAGOPALAN, Kanavillil. Por uma linguística crítica: linguagem, identidade e questão ética. São Paulo: Parábola Editorial, 2003. 
ROJO, Roxane. (org.). Escol@ conectada: os multiletramentos e as TICs. São Paulo: Parábola, 2013.

STREET, B. Letramentos sociais: abordagens críticas do letramento no desenvolvimento, na etnografia e na educação. Trad. Marcos Bagno. São Paulo: Parábola, 2014.

Data de submissão: 07/08/2020. Data de aprovação: 23/10/2020. 